\title{
TREATMENT OF METHICILLIN-RESISTANT STAPHYLOCOCCUS AUREUS (MRSA) SEPSIS WITH COMBINATION OF FOSFOMYCIN AND AMIKACIN IN A PATIENT WITH SCALD-BURN INJURY
}

\author{
OKI NUGRAHA PUTRA ${ }^{1 *}$, ISWINARNO DOSO SAPUTRO², ANA KHUSNUL F ${ }^{3}$ \\ ${ }^{1}$ Departement of Pharmaceutics, Study Program of Pharmacy, Faculty of Medicine, Hang Tuah University, Surabaya, Indonesia. \\ ${ }^{2}$ Departement of Plastic Surgery and Reconstructive, Dr. Soetomo Hospital, Surabaya, Indonesia. ${ }^{3}$ Departement of Clinical Pharmacy, Study \\ Program of Pharmacy, Faculty of Medicine, Hang Tuah University, Surabaya, Indonesia. Email: okinugrahaputra@yahoo.com
}

Received: 15 February 2018, Revised and Accepted: 23 March 2018

ABSTRACT

Objective: Methicilin resistant Staphylococcus aureus (MRSA) leads a serious major problem such as well as nosocomial infection especially in clinical burn setting. Management of MRSA infection becomes more complex in clinical settings due to its extension of resistance towards much class of antibiotics and it is purely based on antibiotic susceptibility. This case report assesses the efficacy combination of fosfomycin and amikacin in the management of MRSA infection in a burn patient.

Methods: A 31-year-old male was transferred to the burn center for definitive treatment. Initially, the patient was treated with ceftazidime injection as empiric antibiotic $1 \mathrm{~g} 3$ times daily, but the patient became sepsis during the treatment. Blood specimen was taken and MRSA was isolated from this culture. The patient was isolated and based on antibiotic susceptibility, the patient was started on fosfomycin $2 \mathrm{~g}$ IV twice daily for first 7 days, and after that fosfomycin was combined with amikacin IV $500 \mathrm{mg}$ once daily.

Results: After administration of these antibiotics, a rapid clinical improvement was observed with the patient, leucocytosis did not occur and blood culture was negative. The patient completed a total of 14 days of fosfomycin and 8 days of amikacin therapy.

Conclusion: The synergistic combination of fosfomycin with amikacin, may be useful alternative treatment option for sepsis related MRSA in burn injury. Further research is also needed to clarify effectiveness of fosfomycin and amikacin to treat MRSA infection in burn patient.

Keywords: Methicilin-resistant Staphylococcus aureus, Scald burn, Sepsis, Fosfomycin, Amikacin.

(c) 2018 The Authors. Published by Innovare Academic Sciences Pvt Ltd. This is an open access article under the CC BY license (http://creativecommons. org/licenses/by/4. 0/) DOI: http://dx.doi.org/10.22159/ajpcr.2018.v11s3.30018

\section{INTRODUCTION}

Infections caused by methicillin-resistant Staphylococcus aureus (MRSA) are a frequent occurrence in most medical centers, especially in patients admitted to the intensive care (IC) unit for prolonged periods of time [1]. In burned individuals, death due to the failure of initial resuscitation has been uncommon in recent years. Sepsis, despite the advent of potent new antibiotics, is now the major cause of death in these patients. The appearance of drug-resistant organisms is a common consequence of the injudicious use of antimicrobials, as exemplified by the emergence of MRSA [2].

MRSA, which always exhibits multiple antibiotic resistance in clinic manifestation, is one of the most important pathogenic species that may result in a severe shock to death [3]. To the best of our knowledge, severe burn patients are more susceptible to MRSA infection because of losing the protective skin barrier and immunological variations. The outbreak of MRSA infection in burn patients has been widely reported, and the persistence of MRSA in burn units has been proved by more and more evidence [4]. In the past few years, the prevalence of MRSA isolated from clinical isolates, especially in burn patients, increased sharply in China [5].

Historically vancomycin, a glycopeptide antimicrobial, has been the treatment of choice for MRSA infections. However, the clinical utility of vancomycin has recently been questioned when employed in the treatment of MRSA infections when the mean inhibitory concentration (MIC) of vancomycin is $>1 \mathrm{mg} / \mathrm{L}$, with published literature reporting increased treatment failure and mortality in patients due to inability to attain currently established pharmacokinetic (PK) and pharmacodynamic (PD) targets [6,7].
Although antimicrobials such as vancomycin have been shown to be effective in controlling MRSA infection, MRSA remains a common cause of death in burn patients. Fosfomycin was described originally by Hendlin and associates more than three decades ago. Fosfomycin was effective in controlling infection caused by MRSA, especially when combined with other antimicrobial agents $[8,9]$. We described a case of MRSA in a patient with scald burn injury who did not respond to initial ceftazidime therapy but responded clinically to treatment with fosfomycin-amikacin.

\section{PRESENTATION OF CASE}

A 31-year-old male sustained scald burn at the steam-powered electric generator in August 2016. He was conservatively managed including debridement at once in a private hospital at Pati, Centre of Java and brought to the Dr. Soetomo Hospital for further management. At admission, he was at the $9^{\text {th }}$ day after the injury. On general examination, the patient was conscious, oriented, afebrile, not anemic, normal leukocyte and albumin level, not a known history of diabetes mellitus or hypertension and not sepsis. On local examination, he was diagnosed at $37.5 \% 2^{\text {nd }}$ degree burns present in regimen facialis with burned eyelashes, thoracoabdominalis, extrimitas superior, extrimitas inferior, and genitalia externa.

Initially, the patient was treated with injection ceftazidime intravenously (IV) $1 \mathrm{~g} 3$ times daily for 7 days along with supportive drugs, and during the hospitalization, surgery (debridement) was done for 3 times. Wound debridement was done under closely supervised by plastic surgeon and anesthesiologist. Soon after the debridement, wound was treated with a dressing containing silver. The patient completed 
a total of 7 days of ceftazidime, but at $5^{\text {th }}$ days of ceftazidime therapy, the patient became leukocytosis $\left(>27.10^{3}\right)$ and fever and diagnosed as bacteremia or sepsis. It seems that the patient unresponsive to ceftazidime. Blood specimen was taken from the right and left venous vessel aseptically and processed by microbiological procedures. MRSA was isolated in culture. Antibiotic susceptibility was performed by Kirbi-Bauer disk diffusion method where the isolate was found to be sensitive to tetracyclin, erytromicin, clindamycin, quinupristindalfopristin, fosfomycin, and vancomycin. The isolate of MRSA was found to be resistant to gentamicin, ampicillin, ampicillin-sulbactam, penicillin G, oxacillin, chloramphenicol, levofloxacin, and moxifloxacin. The patient was isolated and treated with injection fosfomycin $2 \mathrm{~g} \mathrm{IV}$ twice daily for the first 7 days and after that fosfomycin was combined with amikacin IV $500 \mathrm{mg}$ once daily. The patient completed a total of 14 days of fosfomycin and 8 days of amikacin therapy. At the end of antibiotics therapy, blood specimen was taken, and the bacterial culture was negative.

\section{DISCUSSION}

MRSA is a widespread pathogen both in the community and in hospital settings. Infection of burn wound patients with MRSA and pathogen causes higher morbidity and mortality which may contribute death in about three-fourths of the burn wound infected patients [10]. Due to imprudent uses and suboptimal doses of antibiotics, common pathogenic microorganism develops antimicrobial resistance against commonly used drugs. It increases the burden of the patient as well as national cost in the health-care sectors. In our study, MRSA was isolated from the scald burn patient. In burns, breaching skin barriers provide a suitable site for bacterial multiplication and are more persistent richer sources of infection than any other surgical wounds, mainly because of the larger area involved and longer duration of patient stay in the hospital [11].

For this reason, special attention to hospital infection should be paid in burns unit by early interventions should be performed to improve the quality of treatment. Antibiotics are frequently administered at random, without obtaining the results or without respect to the principles of rational antibiotic therapy. On the other hand, the usage of antibiotics is one of the main risk factors for nosocomial infections. Excessive use of antibiotics stimulates the development of antibioticresistant bacteria, increases treatment costs, and causes side effects. This can be avoided by rational use of antimicrobials, i.e., only when necessary, with a careful choice of the suitable drugs [12]. Methicillin resistance in $S$. aureus is a gold standard for multidrug resistance, mainly to penicillin family (such as cephalosporins, ampicillin, and amoxicillin), ticarcillin-clavulanic acid, piperacillin-tazobactam, and the carbapenems regardless of the susceptibility testing results $[13,14]$ and our report also supports the same.

To date, there only have been limited data on MRSA in Indonesia. An early study conducted in 2001 identified 1 (0.3\%) MRSA isolates among 329 S. aureus nares flora from 3,995 patients [15]. By 2011, in three teaching hospitals (Denpasar, Semarang, and Malang) in Indonesia, screening of 1,502 surgery patients at the time of discharge by culturingnares, throat and skin lesion, revealed a MRSA carriage rate of 4\% [16]. Our patient with diagnosed as $37.5 \% 2^{\text {nd }}$ degree burn, categorized as a severe burn. In the case of a severe burn, the probability of MRSA infection increases, since the patients spend more time in the hospital, and undergo more frequent debridements and dressings [17]. The similar thought applies to surgical procedures. It could be argued that the severity of the burns itself was the reason for additional operation, which, in turn, increased the risk to test positive for MRSA [18].

Ceftazidime is widely used to treat burn patients, but few data are available on its PKs in this group. The standard dosage recommendations for beta-lactam antibiotics can result in very low drug levels in IC patients and burn patients in the absence of renal dysfunction. In this study, the patient was given ceftazidime $1 \mathrm{~g} 3$ times daily but showed no signs of clinical improvement. Alteration in the physiological response to a burn makes dosing medication, especially antibiotics, challenging in burn patients.

A study by Conil et al., 2007, carried out the PKs of ceftazidime in burn patients with daily doses of $1 \mathrm{~g} \times 6(\mathrm{n}=17)$. The results showed that the ratio of C ( $\mathrm{min}$ ) to the low MIC breakpoint ( $4 \mathrm{mg} / \mathrm{l}$ ) was lower than 4 in $52 \%$ of subjects receiving ceftazidime. The C ( $\mathrm{min}$ ) of ceftazidime was correlated with measured creatinine clearance (CLCR) and was higher in mechanically ventilated patients than in non-ventilated patients. The clearance of ceftazidime was correlated with age. Therefore, dosage adjustment of these drugs in burn patients needs to take into account age, measured CLCR and the danger of low concentrations occurring when the CLCR is $>120 \mathrm{ml} / \mathrm{min}$. In burn patients, the PK disposition of ceftazidime was much more variable than in healthy subjects. Age and CLCR were predictors of the disposition of this antibiotics. Shortening the dosage interval or using continuous infusions will prevent low serum levels and keep trough levels above the MIC for longer periods of time [19].

Fosfomycin has a broad spectrum of activity against a wide range of Gram-positive and Gram-negative bacteria. Its unique mechanism of action may provide a synergistic effect to other antibiotics including beta-lactams, aminoglycosides, and fluoroquinolones [20-22] Recently, intravenous fosfomycin has been administered in critically ill patients with sepsis or nosocomial-acquired infections due to MRSA, vancomycin-resistant Enterococcus, and MDR Gram-negative bacteria, especially carbapenem-resistant Klebsiella pneumoniae, in combination with other antibiotics, due to its unique mechanism of action and its protective effect against nephrotoxicity induced by aminoglycosides or colistin [23-25]. Rationale for combining fosfomycin with a second antimicrobial agent is to prevent the emergence of fosfomycin resistant strains. Fosfomycin is approved in several European countries for the therapy of soft tissue infections and sepsis. In our patient, amikacin $500 \mathrm{mg}$ daily was administered with fosfomycin.

In healthy subjects, amikacin exhibits low protein binding $(<10 \%)$ and a volume of distribution of $0.20-0.25 \mathrm{~L} / \mathrm{kg}$. Unmetabolized amikacin is eliminated in an active form through renal mechanisms, essentially by glomerular filtration. PK changes noted in burn patients are an increased volume of distribution and altered renal clearance [26]. Due to the PK alterations observed in burn patients, inadequate peak concentrations (Cmax) are frequent when using multiple-daily dosing regimens [27]. Aminoglycosides exhibit a concentration-dependent bactericidal effect, and many reports have shown the merits of once-daily dosing (ODD) regimen $[28,29]$. The ODD regimen is based on PD, bacteriological, and toxicological principles. It enables optimization of the $\mathrm{C}_{\max } / \mathrm{MIC}$ ratio as well as efficacy while ensuring an "aminoglycoside-free" period during a $24 \mathrm{~h}$ interval, thus decreasing toxicity [30-32]. In this study, amikacin was administered $500 \mathrm{mg}$ once daily. Our study is similar to Conil et al., who recorded plasma concentration following administration of $20 \mathrm{mg} / \mathrm{kg}$ amikacin in burn patients. It conclude that ODD regimens of amikacin in patients with burns $>15 \%$ body surface area and/or with ClCR $>120 \mathrm{ml} / \mathrm{min}$ could require doses $>20 \mathrm{mg} / \mathrm{kg}$ to reach adequate $\mathrm{C}_{\max }[33]$. Amikacin is one of a aminoglycosides antibiotics, clearance of aminoglycosides was increased in burns patients that caused lower $\mathrm{C}_{\max }$ values and loss of aminoglycosides was caused by greater percentage total body surface area $[33,34]$.

Swab specimen was taken by several days of antibiotics administration, and Acinetobacter baumannii was found from this swab. Antibiotic susceptibility was performed and the isolate resistant to amikacin, tobramycin, gentamycin, astreonam, amoxicillin-clavulanic acid, cefazoline, ceftazidime, cefotaxime, ceftazidime, cefoperazone-sulbactam, tetracycline, ciprofloxacin, levofloxacin, fosfomycin, meropenem, and ertapenem. Although the bacteria are resistant to fosfomycin and amikacin, at the end of these antibiotics therapy for 14 days, blood specimen was taken, and the bacterial culture was negative. 
A study by Montgomery et al. showed that for A. baumannii strains, the effect was most pronounced for strains with high amikacin resistances (MIC $>1024 \mu / \mathrm{ml}$ ), but amikacin MIC values were reduced $<256 \mu / \mathrm{ml}$ with the amikacin/fosfomycin combination. It concluded that combining amikacin in a 5:2 ratio with fosfomycin significantly enhanced the potency of amikacin-resistant pathogen [35].

\section{CONCLUSION}

MRSA acquisition remains a significant problem in burn units. We describes a case of a scald burn injury patient who successfully treated with fosfomycin $2 \mathrm{~g}$ every $12 \mathrm{~h}$ and amikacin $500 \mathrm{mg}$ once daily for documented MRSA sepsis. Larger studies are needed to further evaluate for safety, efficacy, and the appropriate dose based on PKs altered in burn patients. Clinicians should recognize the rational use of antibiotics, adjust treatment accordingly, thus allowing for improved patient outcomes.

\section{ACKNOWLEDGMENTS}

The authors would like to thank all the staff at the burn centre and ICU room for their collaboration during the study

\section{CONFLICTS OF INTEREST}

None declared.

\section{REFERENCES}

1. Jeffres MN, Isakow W, Doherty JA, McKinnon PS, Ritchie DJ, Micek ST, et al. Predictors of mortality for methicillin-resistant Staphylococcus aureus health-care-associated pneumonia: Specific evaluation of vancomycin pharmacokinetic indices. Chest 2006;130:947-55.

2. Nakazawa H, Kikuchi Y, Honda T, Isago T, Nozaki M. Enhancement of antimicrobial effects of various antibiotics against methicillin-resistant Staphylococcus aureus (MRSA) by combination with fosfomycin. J Infect Chemother 2003;9:304-9.

3. Nikfar R, Shamsizadeh A, Ziaei KajbafT, Kamali Panah M, Khaghani S, Moghddam M, et al. Frequency of methicillin-resistant Staphylococcus aureus nasal carriage in healthy children. Iran J Microbiol 2015;7:67-71.

4. Susethira AR, Uma A, Prabhu N., Management of methicillin resistant Staphylococcus aureus infection of endogenous origin in an electrical burns patient-a case report. Br Microbiol Res J 2014;4:1138-41.

5. Yezli S, Li H. Antibiotic resistance amongst healthcare-associated pathogens in China. Int J Antimicrob Agents 2012;40:389-97.

6. Haque NZ, Zuniga LC, Peyrani P, Reyes K, Lamerato L, Moore CL, et al. Relationship of vancomycin minimum inhibitory concentration to mortality in patients with methicillin-resistant Staphylococcus aureus hospital-acquired, ventilator-associated, or health-care-associated pneumonia. Chest 2010;138:1356-62.

7. Sakoulas G, Moise-Broder PA, Schentag J, Forrest A, Moellering RC Jr. Eliopoulos GM, et al. Relationship of MIC and bactericidal activity to efficacy of vancomycin for treatment of methicillin-resistant Staphylococcus aureus bacteremia. J Clin Microbiol 2004;42:2398402.

8. Niida M, Yoshida T, Kohmoto A, Ogawa M, Hashimoto H, Deguchi K, et al. Studies on the combined effect of fosfomycin with sulbactam/ cefoperazone on methicillin-resistant Staphylococcus aureus and Pseudomonas aeruginosa. Jpn J Antibiot 1994;47:1-0.

9. Misawa S, Tsuda S, Taniwaki M, Horiike S, Ariyama Y, Hirakawa K, et al. A combined consecutive therapy with fosfomycin and sulbactam/ cefoperazone for bacterial infections associated with hematological diseases. Jpn J Antibiot 1995;48:514-21.

10. Tenover FC. Mechanisms of antimicrobial resistance in bacteria. Am J Med 2006;119:S3-10.

11. Nakao M, Senda Y. An epidemiological investigation of hospital infections caused by MRSA and their prevention. Kawasaki J Med Welf. 2006;11:1-11.

12. Begier EM, Frenette K, Barrett NL, Mshar P, Petit S, Boxrud DJ, et al. A high-morbidity outbreak of methicillin-resistant Staphylococcus aureus among players on a college football team, facilitated by cosmetic body shaving and turf burns. Clin Infect Dis 2004;39:1446-53.

13. Seguin JC, Walker RD, Caron JP, Kloos WE, George CG, Hollis RJ, et al. Methicillin-resistant Staphylococcus aureus outbreak in a veterinary teaching hospital: Potential human-to-animal transmission.
J Clin Microbiol 1999;37:1459-63.

14. Lee JH. Methicillin (Oxacillin)-resistant Staphylococcus aureus strains isolated from major food animals and their potential transmission to humans. Appl Environ Microbiol 2003;69:6489-94.

15. Severin JA, Lestari ES, Kuntaman K, Melles DC, Pastink M, Peeters JK, et al. Unusually high prevalence of panton-valentine leukocidin genes among methicillin-sensitive Staphylococcus aureus strains carried in the indonesian population. J Clin Microbiol 2008;46:1989-95.

16. Santosaningsih D, Santoso S, Budayanti NS, Kuntaman K, Lestari ES, Farida H, et al. Epidemiology of Staphylococcus aureus harboring the mecA or panton-valentine leukocidin genes in hospitals in java and bali, Indonesia. Am J Trop Med Hyg 2014;90:728-34.

17. Bagdonas R, Tamelis A, Rimdeika R. Stpahylococcus aureus infection in the surgery of burns. MEDICINA 2003;39:11.

18. Issler-Fisher AC, McKew G, Fisher OM, Harish V, Gottlieb V, Maitz PK. Risk factor for, and the effect of MRSA colonization on the clinical outcome of severly burn patients. Burns 2015;41:1212-20.

19. Conil JM, Georges B, Lavit M, Seguin T, Tack I, Samii K, et al. Pharmacokinetics of ceftazidime and cefepime in burn patients: The importance of age and creatinine clearance. Int J Clin Pharmacol Ther 2007; $45: 529-38$

20. Takahashi K, Kanno H. Synergistic activities of combination of beta lactams, fosfomycin, and tobramycin against Pseudomonas aeruginosa. Antimicrob Agents Chemother 1984;26:789-91.

21. Chin NX, Neu NM, Neu HC. Synergy of fosfomycin with beta-lactam antibiotics against staphylococci and Aerobic gram-negative bacilli. Drugs Exp Clin Res 1986;12:943-7.

22. Okazaki M, Suzuki K, Asano N, Araki K, Shukuya N, Egami T, et al. Effectiveness of fosfomycin combined with other antimicrobial agents against multidrugresistant Pseudomonas aeruginosa isolates using the efficacy time index assay. J Infect Chemother 2002;8:37-42.

23. Souli M, Galani I, Antoniadou A, Papadomichelakis E, Poulakou G, Panagea $\mathrm{T}$, et al. An outbreak of infection due to beta-lactamase klebsiella pneumoniae carbapenemase 2-producing K. Pneumoniae in a greek university hospital: Molecular characterization, epidemiology, and outcomes. Clin Infect Dis 2010;50:364-73.

24. Michalopoulos A, Virtzili S, Rafailidis P, Chalevelakis G, Damala M, Falagas ME. Intravenous fosfomycin for the treatment of nosocomial infections due to carbapenem-resistant Klebsiella pneumoniae in critically ill patients: A prospective evaluation. Clin Microbiol Infect 2010;16:184-6.

25. Yamaguchi Y, Hanaki H, Yanagisawa C, Ikeda-Dantsuji Y, Hashimoto T, Yazaki $\mathrm{H}$, et al. Characterization of beta-lactam antibiotic-induced vancomycin-resistant MRSA (BIVR) in a patient with septicemia during long-term vancomycin administration. $\mathrm{J}$ Infect Chemother 2009; $15: 274-8$.

26. Weinbren MJ. Pharmacokinetics of antibiotics in burn patients. J Antimicrob Chemother 1999; 44:319-27.

27. Loirat P, Rohan J, Baillet A, Beaufils F, David R, Chapman A, et al. Increased glomerular filtration rate in patients with major burns and its effect on the pharmacokinetics of tobramycin. $\mathrm{N}$ Engl $\mathrm{J}$ Med 1978;299:915-9.

28. Marik PE, Lipman J, Kolski S, Scribante J. A prospective randomized study comparing once- versus twice-daily amikacin dosing in critically ill adult and paediatric patients. J Antimicrob Chemother 1991;28:753-64.

29. Barza M, Ioannidis JP, Cappelleri JC, Lau J. Single or multiple daily doses of aminoglycosides: A meta-analysis. BMJ 1996;312:338-45.

30. Hoey LL, Tschida SJ, Rotschafer JC, Guay DRP, Vance-Bryan K. Wide variation in single, daily-dose aminoglycoside pharmacokinetics in patients with burn injuries. J Burn Care Rehabil 1997;18:116-24.

31. Zaske DE, Sawchuk RJ, Strate RG. The necessity of increased doses of amikacin in burn patients. Surgery 1978;84:603-8.

32. Beaucaire G, Leroy O, Beuscart C, Karp P, Chidiac C, Caillaux M, et al. Clinical and bacteriological efficacy, and practical aspects of amikacin given once daily for severe infections. J Antimicrob Chemother 1991;27 Suppl C:91-103

33. Conil JM, Georges B, Berden A, Segonds C, Lavit M, Seguin T, et al. Increased amikacin dosage requirements in burn patients receiving a once-daily regime. Int J Antimicrob Agents 2006;28:226-30.

34. Akers KS, Cota JM, Frei CR, Chung KK, Mende K, Murray CK, et al. Once-daily amikacin dosing in burn patients treated with continuous venovenous hemofiltration. Antimicrob Agents Chemother 2011:55:4639-42.

35. Montgomery AB, Rhomberg P, Abuan T, Jones R. Synergistic effects for a combination of amikacin and fosfomycin aginst selected resistant gram-negative pathogens. Am J Respirat Crit Care Med 2013;2013:14-8. 